Short Communication

\title{
Investigation of the Distribution of Temperature in the Electrochemical Machining Using Multiphysics Simulation
}

\author{
Hua Lin ${ }^{1}$, Xiaochao Zhou, ${ }^{1, *}$, Changyong Cao ${ }^{1}$, Gang Han ${ }^{1}$, Meiyu Sha ${ }^{1}$,Yubao Xu ${ }^{2}$ \\ ${ }^{1}$ School of Mechanical and Automotive Engineering, West Anhui University, Lu'an 237000, China \\ ${ }^{1}$ School of Electrical and Photoelectronic Engineering, West Anhui University, Lu' an 237000, China \\ "E-mail: 39548804@qq.com
}

Received: 25 October 2021 / Accepted: 30 November 2021 / Published: 5 January 2022

\begin{abstract}
The distribution of temperature in the electrochemical machining (ECM) gap is uneven and it is hard to predict and measure it. In this paper, a multiphysics simulation model for the ECM temperature was established. The flow field and the temperature distribution in the gap were solved based on the turbulence model of Standard $k-\varepsilon$, Low Reynolds number $(R e) k-\varepsilon$, Shear stress transfer (SST), and Bubbly flow. The experimental device was built and the calculated and experimental results were compared. It was shown that the solution accuracy of the low Re flow model was higher than that of the high $R e$ flow model. The computed temperature distribution obtained by employing the multiphysics model based on the low $R e$ gas-liquid two-phase flow field was close to the experimentally measured one. This study could provide a basis for the accurate prediction of the anode profile of ECM.
\end{abstract}

Keywords: Electrochemical machining; Turbulent flow model; Low Reynolds number; Multiphysics; Temperature distribution

\section{$\underline{\text { FULL TEXT }}$}

(C) 2022 The Authors. Published by ESG (www.electrochemsci.org). This article is an open access article distributed under the terms and conditions of the Creative Commons Attribution license (http://creativecommons.org/licenses/by/4.0/). 